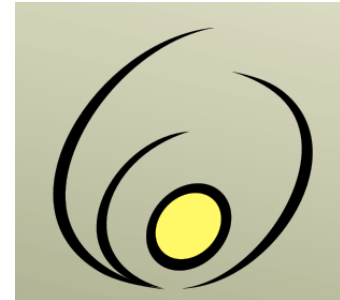

Fórum de Pró-Reitores de Extensão das Instituições Públicas de

Educação Superior Brasileiras

\section{Revista Brasileira de Extensão Universitária}

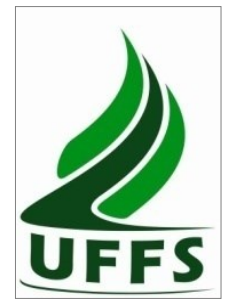

v. 11 , n. 3, p. $417-427$, set.-dez. 2020

e-ISSN 2358-0399

\title{
Contribuições da extensão universitária para a formação acadêmica a partir de um projeto de educação ambiental
}

\author{
Jocimara Peretiatko', Ynaê Martins Osternach², Regiane Matozo Fernandes³, Ana Lucia \\ Suriani Affonso ${ }^{4}$, Rosilene Rebeca5, Adriana Massaê Kataoka ${ }^{6}$
}

\begin{abstract}
Resumo: A formação acadêmica é um processo de investimento profissional e pessoal que merece uma reflexão especial, relacionada à contribuição da extensão. A extensão universitária tem sido apontada como uma dimensão fundamental na formação inicial de acadêmicos, embora nem sempre reconhecida. Assim, este artigo investiga a percepção dos acadêmicos envolvidos no projeto de extensão Crise hídrica: oficinas ecopedagógicas, em relação à contribuição que um projeto de extensão pode trazer para a sua formação, em suas múltiplas dimensões. A pesquisa utilizou uma abordagem qualitativa e o questionário como instrumento de obtenção de informações. Por meio dos resultados obtidos, foi possível verificar que houve uma ampliação do entendimento sobre extensão universitária e em relação aos conhecimentos específicos da área ambiental. Os acadêmicos também revelaram que adquiriram habilidades, como a de se expressar em público, e valores, como o respeito às diferenças, além do desenvolvimento do senso crítico e do desejo de transformar o mundo por meio de sua profissão.
\end{abstract}

Palavras-chave: Universidade; Percepção Ambiental; Oficinas Ecopedagógicas

\section{Contributions of university extension to the academic education through an environmental education project}

Abstract: Academic education is a process that requires professional and personal investments, which deserve a particular reflection related to the contribution of extension courses. The university extension has been considered as a fundamental dimension in the education of university students, although it has not always been acknowledged. Thus, the present article investigates the perception of students involved in the extension project Water crisis: ecopedagogical workshops about the contribution that the extension project could provide for their education in multiple dimensions. The research made use of a qualitative approach and the survey as a tool to gather the information. It was possible to verify a broadened understanding of university extension and the specific expertise in the environmental area through the collected results. The students also revealed that they had improved their abilities toward expressing themselves in public, their values related to differences, in addition to developing critical sense and the wish to change the world through their profession.

Keywords: University; Environmental Perception; Ecopedagogical workshops
Originais recebidos em

15 de abril de 2020

Aceito para publicação em

03 de novembro de 2020

1

Mestranda em Ensino de Ciências Naturais e Matemática -

PPGEN/UNICENTRO.

Rua Simeão Varela de Sá, 03, Vila Carli, Guarapuava/PR. CEP: 85040-080.

(autora para correspondência)

jocimaraperetiatko@hotmail.com

2

Mestranda em Ensino de Ciências

Naturais e Matemática -

PPGEN/UNICENTRO.

ynaeynae@hotmail.com

3

Mestre em Ensino de Ciências Naturais e Matemática - PPGEN/UNICENTRO.

regianefernandesrf@hotmail.com

4

Doutora e docente da Universidade Estadual do Centro-Oeste (UNICENTRO).

analuciabio@gmail.com

5

Doutora e docente da Universidade Estadual do Centro-Oeste (UNICENTRO).

rosilenerebeca@yahoo.com.br

6

Doutora e docente da Universidade Estadual do Centro-Oeste (UNICENTRO).

dri.kataoka@hotmail.com 


\section{Introdução}

Este estudo refere-se ao projeto de extensão Crise hídrica: oficinas ecopedagógicas, desenvolvido pela Universidade Estadual do Centro-Oeste (UNICENTRO) durante os anos de 2015 e 2017, tendo como temática os rios urbanos do município, e fundamentou-se nos princípios da Educação Ambiental (EA) crítica.

Acreditamos que trabalhar a EA, principalmente em sua vertente crítica, por meio da extensão universitária, potencializa seus resultados, uma vez que, dos três pilares da universidade (pesquisa, ensino e extensão), a extensão possui princípios e objetivos mais próximos da EA. A extensão universitária se apresenta como uma inovação na prática acadêmica, devido a sua abordagem interdisciplinar, a associação entre o ensino e a pesquisa, e entre a teoria e a prática. Além disso, busca a transformação social, a partir do contato com o conhecimento acadêmico (Carneiro et al., 2014).

Segundo o Plano Nacional de Extensão Universitária (Fórum de Pró-Reitores de Extensão das Universidades Públicas Brasileiras, 2007, p. 17), entende-se por extensão todo "processo educativo, cultural e científico que articula o Ensino e a Pesquisa de forma indissociável e viabiliza a relação transformadora entre a universidade e a sociedade".

Entretanto, a maioria dos projetos de extensão repassa informações superficiais para a população, sem a percepção de que a extensão pode produzir conhecimentos e contribuir de maneira mais efetiva com a formação dos acadêmicos. Além disso, evidencia-se a falta de discussão e valorização, dentro das universidades, acerca desse tema, o que leva ao desenvolvimento de ações pontuais desvinculadas do ensino e da pesquisa (Proença et al., 2012).

Desta forma, tendo em vista os problemas de muitos projetos de extensão, apontados anteriormente, o projeto focalizado neste estudo enfatizou a temática ambiental a partir de uma perspectiva crítica de EA, buscando a superação dessas dificuldades. Segundo Loureiro (2015), a EA crítica contribui para uma postura que reconhece as diferentes dimensões da vida e busca transformá-las por meio do enfrentamento e da superação da crise socioambiental.

Portanto, projetos de extensão podem ser uma alternativa para garantir a presença da EA nos cursos de Ensino Superior, além de propiciarem condições de formação voltadas para a transformação socioambiental, o que torna relevante a ligação entre a Extensão e a EA (Juliani \& Freire, 2014).

Assim, esta pesquisa investigou a percepção dos acadêmicos envolvidos no projeto de extensão Crise hídrica: oficinas ecopedagógicas, sobre a contribuição que essa imersão trouxe, para a sua formação, em suas múltiplas dimensões, sejam elas profissionais, pessoais e/ou sociais.

\section{Uma breve retomada sobre a origem da Extensão Universitária}

Dentre os três pilares da universidade (ensino, pesquisa e extensão), a extensão universitária foi a última a surgir, porém, ela não é tão recente assim. As primeiras manifestações da extensão ocorreram na Inglaterra, a partir da segunda metade do século XIX. Em seguida, se expandiram por todo o continente europeu, pelos Estados Unidos e pelo Brasil (Paula, 2013).

Nesse cenário, as iniciativas das universidades despertaram a necessidade de se criar um vínculo mais amplo entre universidade e população, iniciando uma discussão sobre uma nova função social, além do ensino e da pesquisa, chamada extensão universitária (Souza, 2005). 
No Brasil, segundo Gurgel (1984), a extensão teve três momentos bem definidos a partir do século XX: o período das experiências pioneiras; o período das experiências isoladas e da disseminação das ideias, bem como do desenvolvimento de ações a partir dos movimentos sociais; e o período de maior institucionalização da extensão universitária.

Em 1968 foi aprovada a Lei n 5.540, conhecida como Lei Básica da Reforma Universitária, a qual institucionalizou a extensão, tornando-a obrigatória nas universidades. Na década de 1980, a sociedade civil se fortaleceu e iniciou-se a construção de um novo padrão de sociedade, cidadania e universidade. A partir desse movimento, foi constituído, em 1987, o Fórum Nacional de Pró-Reitores de Extensão das Universidades Públicas (FORPROEX), principal entidade que articula e define as políticas públicas de extensão, a qual passa a ser definida com o princípio de indissociabilidade com o ensino e a pesquisa (Fórum de Pró-Reitores de Extensão das Universidades Públicas Brasileiras, 2007).

Segundo Jezine (2004), as mudanças políticas, econômicas e sociais que ocorreram, influenciaram discussões acerca da caracterização da extensão, construindo, historicamente, três diferentes concepções de extensão universitária: a concepção assistencialista, a acadêmica e a mercantilista. Estas estão presentes na prática curricular das universidades e expressam diferentes aspectos da integração entre universidade, extensão e sociedade. A primeira concepção foi constituída a partir do surgimento da extensão, como prestação de serviços assistencialistas para a sociedade. A concepção acadêmica, por sua vez, tem se formado por meio dos movimentos sociais, caracterizando-se por vincular ensino-pesquisa e teoria-prática, além de buscar uma ação transformadora da sociedade e possibilitar a formação crítica dos sujeitos. Já a concepção mercantilista surgiu das alterações ocorridas na estrutura da sociedade e do Estado, concomitantemente com a luta da extensão para afirmar-se como função acadêmica e com a mesma valorização da integração ensino-pesquisa (Jezine, 2004).

Para Jezine (2004), essas concepções extensionistas expressam diferentes convicções nos diversos contextos históricos, e se encontram nas práticas curriculares universitárias e nas abordagens teóricas de muitos estudiosos. Portanto, é necessário refletir sobre as implicações que tais concepções podem trazer no tipo de formação de sociedade e sujeitos que se pretende desenvolver.

No entanto, as atividades extensionistas não têm sido adequadamente compreendidas e implementadas pelas universidades, talvez por seu caráter interdisciplinar e característica de transcender salas de aulas e laboratórios, e por atender um público amplo, difuso e heterogêneo (Paula, 2013).

\section{Percurso Metodológico}

A pesquisa foi realizada a partir de uma abordagem predominantemente qualitativa, do tipo pesquisa participante. Segundo Brandão (1987), esse tipo de pesquisa prioriza a interação entre o pesquisador e os participantes da pesquisa, a fim de compreender o fenômeno estudado com maior riqueza de detalhes. A abordagem qualitativa de pesquisa, que é definida como possibilidade de investigação, inicia-se a partir de uma análise com foco mais amplo e que se revela com o desenvolvimento do estudo. O pesquisador obtém dados descritivos, pelo contato direto e prolongado com o objeto de estudo, a fim de compreender os fenômenos segundo a concepção dos sujeitos da pesquisa (Godoy, 1995). O objeto de estudo, nesta pesquisa, foi constituído por acadêmicos participantes do projeto de extensão Crise hídrica: oficinas ecopedagógicas. Embora as análises tenham sido predominantemente qualitativas, em alguns momentos houve a necessidade de obter dados quantitativos, visando a uma comparação das frequências das categorias obtidas.

Como instrumento da pesquisa, utilizou-se um questionário aberto, visando investigar a percepção dos acadêmicos envolvidos no projeto em relação à extensão universitária e a sua contribuição para a formação 
profissional. Cabe destacar que a aplicação do questionário foi realizada durante o andamento do projeto, uma vez que a investigação se refere a um recorte do projeto de extensão. Esse tipo de questionário contempla questões em que o respondente tem uma maior liberdade para escrever suas respostas (Gil, 2008). As questões foram elaboradas de forma a identificar elementos que apontassem para possíveis contribuições da prática extensionista na formação acadêmica. Abaixo estão apresentadas as perguntas do questionário e seus respectivos objetivos.

- Pergunta 1: Qual foi o motivo que o/a levou a participar do projeto de extensão?

Objetivo: Compreender o motivo que orientou/levou os acadêmicos a participarem do projeto.

- $\quad$ Pergunta 2: O que você entendia por extensão universitária antes de entrar no projeto? E após iniciar o projeto?

Objetivo: Investigar se houve evolução no entendimento dos acadêmicos sobre a extensão universitária, com a participação no projeto.

- Pergunta 3: Na sua percepção, participar desse projeto de extensão contribui para sua formação profissional? Em caso afirmativo, descreva em que aspecto(s) contribui.

Objetivo: Identificar os principais aspectos que contribuem para a formação profissional dos acadêmicos participantes do projeto de extensão.

A aplicação do questionário ocorreu durante uma das reuniões semanais do projeto de extensão, realizadas no Laboratório de Educação Ambiental e Ecologia, da UNICENTRO. O projeto teve como participantes acadêmicos do curso de Ciências Biológicas, além de professores da mesma Instituição e a comunidade escolar de três colégios estaduais. $O$ projeto abordou a temática água, mais especificamente os rios urbanos de Guarapuava, estado do Paraná, dentro de uma perspectiva da EA crítica. A temática foi abordada de forma coletiva e participativa, explicitando os aspectos sociais, econômicos, políticos, históricos e ambientais envolvidos na problemática da crise hídrica, vivenciada pelo estado de São Paulo, em 2015, mas que poderia ocorrer também em outros locais, como em Guarapuava. O projeto foi financiado pelo Fundo Municipal de Meio Ambiente (Guarapuava) e foi estruturado em três fases, que consistiram em: I - Diagnóstico socioambiental da comunidade do entorno dos colégios, por meio de entrevistas; II - Intervenção na comunidade escolar por meio de oficinas ecopedagógicas (Oficinas: Percepção ambiental dos estudantes dos colégios; Correntes em EA; Aspectos sociais, econômicos, políticos e ambientais da crise hídrica; Biomonitoramento de ecossistemas aquáticos próximos aos colégios, utilizando-se macroinvertebrados bentônicos); III - Produção de materiais educomunicativos, como folderes, poesias, fanzines, telejornal e jornal mural.

Os sujeitos da pesquisa totalizaram vinte acadêmicos, ou seja, todos os discentes participantes do projeto de extensão, sendo treze do sexo feminino e sete do masculino, e que possuíam idades entre 19 e 25 anos. A maioria dos participantes (55\%) eram voluntários e o restante (45\%) eram bolsistas.

As informações obtidas, por meio do questionário, foram analisadas de acordo com o método de análise de conteúdo, proposto por Bardin (2011). Esse método é definido como um conjunto de múltiplas técnicas de análise, que resultam em uma descrição do conteúdo das mensagens, permitindo compreender o sentido das informações. Para isso, é organizado em três fases, sendo: a pré-análise, a exploração do material e, por fim, o tratamento dos resultados, a inferência e a interpretação. 
A partir do método de análise de conteúdo, os acadêmicos foram representados pelo código "L" (Licenciando), seguido do número atribuído ao questionário, como, por exemplo: acadêmico L1, acadêmico L2. Com o tratamento dos resultados obtidos emergiram categorias para cada pergunta do questionário. Para a pergunta que versava sobre a motivação do ingresso no projeto de extensão emergiram as categorias: oportunidade oferecida por projeto de extensão, aproximação com o ambiente escolar, meio ambiente, aprimoramento na formação docente, conhecimento aplicado e utilitarismo. As categorias que emergiram do questionamento a respeito do conhecimento sobre extensão universitária, antes de ingressarem no projeto, foram: sem conhecimento prévio, relação Universidade/comunidade, projeto nas escolas, extensão de uma disciplina e utilitarista. As percepções sobre o pós-ingresso no projeto foram expressas nas categorias: importância da relação Universidade/comunidade, aplicação do conhecimento e aprimoramento profissional. Já para a pergunta relacionada à percepção da contribuição da extensão para a formação, as categorias foram: aprimoramento pessoal/profissional, ampliação dos conhecimentos, percepção da EA, responsabilidade e trabalho em grupo.

A validação ocorreu por meio da participação dos membros do grupo de pesquisa e do Laboratório de Educação Ambiental e Ecologia, da UNICENTRO. As categorias foram apresentadas ao grupo e foram debatidas em relação à pertinência, sendo coletivamente aceitas ou reelaboradas.

A pesquisa foi aprovada pelo Comitê de Ética em Pesquisa da UNICENTRO, conforme parecer $\mathrm{n}^{\circ}$ 1.863.327/2016.

\section{Resultados e Discussão}

Os resultados e discussão foram organizados em tópicos, que correspondem aos objetivos de cada pergunta do questionário aplicado: Motivação dos acadêmicos para a participação no Projeto de Extensão (Pergunta 1); Ampliação das concepções de Extensão Universitária dos acadêmicos durante a participação no Projeto de Extensão (Pergunta 2); e Análise dos aspectos que contribuem para a Formação Profissional dos acadêmicos participantes do Projeto de Extensão (Pergunta 3).

\section{Motivação dos acadêmicos para a participação no Projeto de Extensão}

A maioria dos acadêmicos (37\%) decidiram participar do projeto Crise hídrica: oficinas ecopedagógicas, em função das oportunidades que consideravam ser oferecidas por projetos dessa natureza, conforme relatou o acadêmico L5: "A experiência que se ganha, trabalhando em projetos desse gênero [...]"; e a convivência citada pelo L1: "[...] o projeto traz conhecimentos incríveis, não só de conteúdo, mas também de convivência, o aprender com o outro e o motivo que me levou a participar".

As respostas mais mencionadas pelos graduandos também foram referentes ao diferencial que a extensão trazia para a profissão, a relação com o curso de graduação e o envolvimento que as atividades proporcionavam, para além da universidade.

A aproximação com o ambiente escolar foi outro motivo bastante citado pelos alunos, com uma frequência de $29,6 \%$ dos participantes. Entre as citações podemos observar que o acadêmico L10 ressaltou que a extensão possibilitava uma maior aproximação com a escola, quando comparada ao estágio supervisionado do curso: "[...] visto que aproxima o meio acadêmico da escola e possibilita vivenciar um pouco do dia-a-dia no ambiente escolar, o que nem sempre é suficiente durante o estágio".

Os relatos dos acadêmicos evidenciaram que a extensão permite aos futuros professores uma maior aproximação com seu campo de atuação, corroborando com os estudos de Menegon et al. (2015), que 
mencionaram que, para os acadêmicos, a extensão é uma importante forma de conhecer e se aproximar da realidade das escolas, o que possibilita a relação professor-aluno e demonstra a situação de seu campo de trabalho.

Pelo fato de o projeto trabalhar a temática ambiental, a partir dos princípios da EA, muitos acadêmicos relataram o interesse pelo estudo do meio ambiente, que apareceu em $14,8 \%$ das citações. Essa categoria foi subdividida em duas outras, sendo uma em relação ao interesse pela área ambiental (7,4\%), como destacou o acadêmico L16: "[...] como eu me interesso muito pela área ambiental, eu resolvi participar"; e outra com o interesse pelo próprio campo da EA (7,4\%), citado por L9: "O tema educação ambiental, muito próximo de um tema que tenho muita afinidade que é agroecologia".

Ressalta-se, portanto, que a EA, em conjunto com a extensão universitária, é importante para que os indivíduos se tornem ativos no processo de transformação socioambiental, estimulando o desenvolvimento sustentável (Proença et al., 2012).

Outros motivos mencionados pelos acadêmicos para ingressarem no projeto relacionam-se às seguintes categorias: Aprimoramento na formação docente e Conhecimento aplicado (ambas totalizando 7,4\%). No que se refere ao aprimoramento na formação docente, o acadêmico L10 destacou: "[...] dessa forma comecei a participar pois me pareceu ótimo para minha formação [...]". É importante destacar que os acadêmicos, durante sua participação no projeto, praticaram a docência em oficinas, bem como participaram na criação destas, e tiveram a oportunidade de desenvolver atitudes, como proatividade e empatia.

Nesse sentido, a extensão é um dos elementos que contribui, de maneira significativa, com a formação docente e de profissionais que atuarão na Educação Básica, sendo capaz de desenvolver a autonomia progressiva do licenciando (Martins et al., 2016).

A oportunidade de trabalhar teoria e prática é observada pelo acadêmico L3: "E colocar em prática o que vemos na teoria. Assim trabalhamos teoria e prática". Menegon et al. (2015), ao investigarem a importância da extensão universitária na formação inicial de professores, destacam que a extensão possibilita conciliar a relação entre teoria e prática, o que demonstra ser importante para o processo de formação.

A categoria Utilitarismo obteve a menor frequência $(3,7 \%)$, na qual o acadêmico L13 mencionou que, num primeiro momento, o motivo para entrar no projeto relacionava-se com a contribuição da bolsa remunerada, além do enriquecimento do currículo: "Primeiramente o motivo principal foi pela bolsa oferecida pelo projeto, e pelas horas adicionais para o currículo".

Portanto, a partir dos projetos de extensão, além das bolsas remuneradas oferecidas aos participantes, podese enriquecer o currículo acadêmico, por meio da produção de conhecimento de pesquisas e estudos. Desta forma, a partir desse projeto de extensão, oportunizou-se a elaboração e publicação de diversos trabalhos em vários eventos, tais como: artigos, resumos expandidos e simples, iniciação científica e monografias; propiciando ricas experiências para os acadêmicos. Dessa forma, a extensão se configura como fonte de informações para a academia, pois possibilita a publicação e a divulgação de experiências resultantes das atividades extensionistas (Menegon et al., 2015).

\section{Ampliação das concepções de Extensão Universitária dos acadêmicos durante a participação na} Extensão

É importante explicar que esta pesquisa teve como motivação a manifestação dos acadêmicos participantes do projeto de extensão sobre a falta de experiência na extensão, e como esta agregou aspectos positivos para sua formação. Assim, a pesquisa teve início após os sujeitos terem iniciado a participação no projeto. As citações dos licenciandos, referentes à Pergunta 2, evidenciam que não dispunham de conhecimento prévio 
(41,2\%), isto é, não possuíam nenhuma ideia do que tratava a extensão universitária, conforme expresso por L3: "Não tinha conhecimento sobre extensão, somente após que entrei no laboratório".

A concepção de extensão como relação entre universidade e comunidade, ou seja, como transmissão de conhecimentos acadêmicos, foi mencionada por 23,5\% dos universitários. Por exemplo: "Sempre entendi extensão universitária como uma forma de transmissão de informações entre a Universidade e a comunidade em geral" (L10). Essa concepção, de que a comunidade é vista somente como receptora de conhecimentos trazidos pela universidade, foi adotada pelo modelo de extensão das universidades populares europeias, no Século XIX; e possuíam como objetivo disseminar os conhecimentos técnicos para a sociedade, o que levou a uma relação mais ampla e a um contato mais direto desta com a universidade, porém, de forma tecnicista (Souza, 2005). Embora essa concepção tenha sido importante para a época, por ter ampliado a relação entre universidade e sociedade, na atualidade é considerada uma concepção ultrapassada, já que, a partir da extensão, discute-se a produção do conhecimento de forma coletiva.

Alguns acadêmicos (17,6\%) entendiam a extensão como oficinas ou projetos a serem desenvolvidos em escolas sobre um ou mais temas, como cita L13: "Eu achava que era um projeto que se aplicava nas escolas sobre diferentes temas".

As categorias menos citadas pelos licenciandos (5,9\%) foram: Extensão de uma disciplina, Utilitarista e Outros. Inferimos, a partir das definições superficiais sobre extensão universitária apresentadas pelos acadêmicos, e que dispunham antes do projeto, que a extensão é pouco discutida na universidade, ou seja, não vem sendo reconhecida e valorizada como essencial no processo de formação. Isso corrobora com os resultados de Proença et al. (2012), que evidenciaram a falta de discussão e valorização da extensão dentro da universidade, sendo este um fator limitante das ações extensionistas. Os autores também propuseram a necessidade de mais debates sobre a função social da universidade, bem como sobre o equilíbrio entre a formação profissional/técnica e humana/cultural.

Esse é um dos problemas que a extensão enfrenta nas universidades, porém, segundo Costa (2018), outros fatores precisam ser incorporados nessa discussão, como a maior valorização da pesquisa acadêmica em detrimento da relação entre comunidade e universidade, dificultando, assim, a efetivação do princípio da indissociabilidade, além de dificuldades em relação ao financiamento de ações de extensão, temporalidades, negociações e institucionalidades.

Após a participação no projeto, a maioria dos participantes (69\%) perceberam a importância da relação entre a universidade e a população em geral, incluindo a comunidade escolar. Essa categoria mais abrangente foi subdividida em duas subcategorias, mais específicas, a saber: Aproximação universidade-comunidade $(41,4 \%)$ e Universidade-comunidade ativa (27,6\%).

A aproximação entre a universidade e outros setores sociais foi mencionada claramente em algumas citações, como a do acadêmico L5: "Agora entendo que são projetos que obrigatoriamente buscam a aproximação Universidade, comunidade e comunidade escolar". Cabe destacar que, no início do projeto, a aproximação da universidade ocorreu com a comunidade escolar, e, a partir do seu desenvolvimento, expandiu-se para as comunidades do entorno dos colégios e ao poder público. Essa expansão foi materializada pela construção e distribuição do material educomunicativo, pois envolveu a participação do poder público e de membros da comunidade.

É importante lembrar que a extensão universitária busca romper com a visão fragmentada encontrada nas universidades e, assim, ser o meio de articulação recíproca entre a universidade e a sociedade (Jezine, 2004). Ao comparar a fala dos acadêmicos com a evolução das concepções de extensão, verificamos que muitos deles não entenderam a extensão como um processo de mão dupla, isto é, uma construção e troca conjunta de 
saberes entre universidade e comunidade. Contudo, avançaram em relação às suas concepções iniciais, pois perceberam a importância da relação entre universidade e sociedade. Cabe destacar que essa pesquisa enfatiza um recorte do projeto de extensão e, portanto, a partir da constatação das fragilidades dos acadêmicos, estas se tornaram prioridades, que foram trabalhadas no decorrer do projeto.

Alguns acadêmicos $(13,8 \%)$ responderam que, após o início da participação no projeto, puderam perceber que a extensão se refere a uma ação de conhecimentos aplicados (teórico-práticos) ou, ainda, a partir da extensão puderam ampliar ou adquirir outros conhecimentos. Essa explicação pertence à categoria Ampliação de conhecimentos, por exemplo: "Hoje entendo a extensão como um modo de ação, mas com muito estudo e teoria" (L3).

Por meio da extensão, o estudante constrói seu conhecimento e o torna mais complexo, pois consegue fazer relação entre a teoria e a prática (Proença et al., 2012). Assim, o conhecimento é fundamental para uma visão crítica da realidade e para uma atuação concreta sobre as problemáticas ambientais.

Uma parte dos licenciandos (13,8\%) compreendeu que a extensão é fundamental para o aprimoramento profissional e pessoal, como cita o acadêmico L4: "[...] age de forma a trazer maturidade, experiência $e$ compreensão".

É importante que a extensão universitária seja entendida como função acadêmica da universidade, atuando na formação de educadores, pela interdisciplinaridade entre as práticas de ensino e pesquisa, pela integração entre pensar e fazer, e pela relação entre teoria e prática na produção do conhecimento (Jezine, 2004).

Verificamos que as concepções de extensão universitária dos licenciandos foram ampliadas com a participação no projeto, e aqueles que, a princípio, não possuíam conhecimento prévio sobre o assunto, passaram a compreender ao menos a importância da relação entre a comunidade e a universidade. Nesse sentido, essa abordagem de extensão auxilia no aprimoramento profissional e pessoal dos extensionistas, contribuindo para o processo de formação crítica. Para Menegon et al. (2015), a extensão universitária tem papel relevante para um processo de formação diferencial na vida dos acadêmicos participantes, oportunizando o desenvolvimento do senso crítico e do conhecimento significativo.

\section{Análise dos aspectos que contribuem para a Formação Profissional dos acadêmicos participantes}

Todos os licenciandos afirmaram que a extensão contribuiu para a formação profissional. Mais da metade dos acadêmicos $(56,2 \%)$ citaram como principal contribuição do projeto Crise hídrica: oficinas ecopedagógicas o aprimoramento profissional e pessoal.

Entre os exemplos, observou-se que os acadêmicos mencionaram a experiência que se ganha na prática docente, o conhecimento da realidade das escolas, e, também, o desenvolvimento de um pensamento mais crítico sobre diversas questões, como representado em uma das citações: "Contribui para que os alunos de licenciatura adquiram uma maior experiência na docência. Contribui para nossa formação pessoal, influenciando no nosso modo de lidar e pensar as questões ambientais" (L15). Além disso, outros acadêmicos relataram que a extensão contribuiu na formação de valores pessoais, na compreensão das diferenças pessoais, na comunicação, na experiência em falar em público e na motivação em sua futura profissão.

Em pesquisa semelhante, Biondi e Alves (2011) constataram que projetos dessa natureza são importantes para o desenvolvimento acadêmico, sendo que as contribuições mais citadas pelos extensionistas foram a prática de ensino como contribuição profissional e, como contribuição pessoal, vencer a timidez e conseguir falar em público. 
A categoria Ampliação de conhecimentos (25\%) foi a segunda mais citada das contribuições que o projeto trouxe para seus participantes, sendo evidenciada na seguinte citação de L6: "Os grupos de estudo permitiramme aumentar meus conhecimentos teóricos [...]".

Menegon et al. (2015) reforçaram, com sua pesquisa, que as atividades extensionistas na formação inicial são significativas e relevantes para a construção e reconstrução de conhecimentos, de forma ativa e participativa, tornando a prática profissional dos participantes mais efetiva e concreta.

A Percepção de EA, a Responsabilidade e o Trabalho em grupo foram as categorias que emergiram em mesma frequência (6,2\%). A contribuição para uma nova perspectiva de EA foi citada por L18: "Contribui mais pela educação ambiental crítica [...]".

Cabe explicar que o referido projeto adotou a perspectiva crítica da EA. Assim, os participantes puderam conhecer os fundamentos desta EA, que Loureiro (2012) também denomina de Transformadora ou Emancipatória, a qual se fundamenta na prática transformadora da sociedade em um entendimento complexo e dialético da realidade, na qual as problemáticas ambientais se definem historicamente nas relações sociais vigentes. Nesse sentido, Juliani e Freire (2014) argumentam que a EA e a extensão universitária compartilham ideias de transformação da sociedade, sendo importante essa junção.

No que diz respeito à responsabilidade que se adquire durante a participação no projeto, esta foi mencionada por L17: "[...] também a questão de ser responsável, cumprir horários em que são colocados também, e fazer as atividades que são solicitadas". Essa questão é importante, pois sabemos que um dos desafios dos professores e dos educadores ambientais é a responsabilidade.

A questão de trabalhar em grupo na extensão, por sua vez, foi apontada como uma dificuldade encontrada pelos extensionistas e evidenciada como uma das contribuições do projeto, conforme representado pela resposta de L7: "[...] também na melhora das relações do trabalho em grupo". Esse fato reforça o que Biondi e Alves (2011) afirmaram em seu estudo, que uma das contribuições da extensão é saber trabalhar em equipe. É importante aprender a trabalhar em grupo na extensão universitária para adquirir aprendizagens, para desenvolver atitudes e habilidades, para o domínio de conhecimentos relacionados à comunicação, para a formação da personalidade docente, para a formulação de conceitos pessoais, bem como para a construção, desconstrução e reconstrução de crenças. Todos esses fatores favorecem a aprendizagem de melhor qualidade, auxiliando na formação de futuros docentes (Nozaki et al., 2015).

Constatou-se, portanto, que o projeto de extensão contribuiu em várias dimensões para a formação dos licenciandos, inclusive no aprimoramento profissional e pessoal, na ampliação de conceitos, na perspectiva de EA, na responsabilidade e no trabalho em grupo, corroborando com os resultados de Santos et al. (2016), os quais apontam para a importância da extensão no processo de formação profissional, acadêmica e pessoal de alunos extensionistas.

Enfim, consideramos que a ligação entre a EA e a extensão universitária para a formação docente é um importante caminho para que as universidades possam contribuir na preparação da atuação profissional de futuros professores, já que ambas possuem como objetivo comum a transformação social. Nesse sentido, é necessário que as universidades insiram e pratiquem a EA na formação superior, valorizando a extensão universitária como espaço essencial para o processo de formação, tanto profissional quanto pessoal.

\section{Considerações Finais}

A percepção dos acadêmicos envolvidos no projeto de extensão Crise hídrica: oficinas ecopedagógicas revelou que a participação em projetos dessa natureza contribui, de maneira efetiva, para a formação dos futuros 
profissionais. A elaboração das oficinas envolveu, em um primeiro momento, a apropriação teórica dos acadêmicos e, em seguida, desenvolveu o aspecto metodológico destas, bem como a sua aderência com a comunidade. A aplicação das oficinas possibilitou o desenvolvimento de habilidades, como: a oratória, a escuta, e a autonomia e a aptidão em lidar com imprevistos e incertezas.

Os acadêmicos demonstraram, a princípio, uma vaga ideia do que seria a extensão universitária, mas as concepções foram ampliadas após a participação no projeto.

A ampliação de conhecimentos específicos, principalmente no que se refere à temática ambiental foi nítida. $\mathrm{O}$ que mais chamou a atenção foram as afirmações sobre a aquisição de novas habilidades e valores, mencionadas pelos acadêmicos, como a habilidade de falar em público e de trabalhar em grupo, além de valores relacionados ao respeito às diferenças e à consciência da responsabilidade profissional, como meios para transformar o mundo.

Assim, verificamos que a extensão, se comparada aos outros pilares da universidade (ensino e pesquisa), possui características únicas, como propiciar o contato direto do acadêmico com toda a complexidade da sua futura profissão, exigindo que este acesse tudo o que já aprendeu e desenvolva as lacunas que, porventura, existam. Dessa forma, os discentes podem complementar a sua formação em suas múltiplas dimensões.

\section{Agradecimentos}

Agradecemos à UNICENTRO pelo espaço concedido; ao Fundo Municipal de Meio Ambiente de Guarapuava, pelo apoio financeiro; e aos colégios e acadêmicos participantes da pesquisa, pelo envolvimento no projeto.

\section{Contribuições de cada autor}

Os autores J.P., Y.M.O e R.M.F. participaram da redação do artigo; A.M.K., A.L.S.A. e R.R. contribuíram no planejamento e na revisão intelectual crítica do tema abordado; A.M.K. e A.L.S.A. atuaram como coordenadoras do projeto de extensão, além de contribuírem com a redação final do artigo.

\section{Referências}

Bardin, L. (2011). Análise de conteúdo. São Paulo: Edições 70.

Biondi, D., \& Alves, G. C. (2011). A extensão universitária na formação de estudantes do curso de engenharia florestal, UFPR. Revista Eletrônica do Mestrado em Educação Ambiental, 26, 209-224.

Carneiro, P. C. O., Collado, D. M. S., \& Oliveira, N. F. C. (2014). Extensão universitária e flexibilização curricular na UFMG. Interfaces - Revista de Extensão, 2(3), 4-26.

Costa, J. F. A. (2018). Articulação entre pesquisa, ensino e extensão: Um desafio que permanece. Revista Ciência em Extensão, 14(2), 9-19.

Fórum de Pró-Reitores de Extensão das Universidades Públicas Brasileiras. (2007). Extensão Universitária: Organização e Sistematização. Belo Horizonte: Coopmed. Recuperado de http://www.pec.ufv.br/wp-content/uploads/2016/ 05/Organizacao-e-Sistematizacao.pdf

Gil, A. C. (2008). Métodos e Técnicas de Pesquisa Social. 6. ed., São Paulo: Atlas.

Godoy, A. S. (1995). Introdução à pesquisa qualitativa e suas possibilidades. Revista de Administração de Empresas, $35(2), 57-63$.

Gurgel, R. M. (1984). Extensão universitária: Comunicação ou domesticação? Educação em Debate, 6(7), 53-60. 
Jezine, E. (2004). As Práticas Curriculares e a Extensão Universitária. Anais do Congresso Brasileiro de Extensão Universitária, Belo Horizonte, 2. Belo Horizonte: UFMG. Recuperado de https://www.ufmg.br/congrext/ Gestao/Gestao12.pdf

Juliani, S. F., \& Freire, L. (2014). O papel da extensão universitária na inserção curricular da Educação Ambiental: uma experiência no curso de Ciências Biológicas da UFRJ. Revista da SBEnBIO - Associação Brasileira de Ensino de Biologia, 7, 6723-6734.

Loureiro, C. F. B. (2012). Trajetória e fundamentos da educação ambiental. 4. ed. São Paulo: Cortez.

Loureiro, C. F. B. (2015). Educação Ambiental e Epistemologia Crítica. Revista Eletrônica do Mestrado em Educação Ambiental 32(2), 159-176.

Martins, R. E. M. W., Dias, J., \& Martins Filho, L. J. (2016). O contexto do ensino, pesquisa e extensão na formação docente na Faculdade de Educação da Universidade do Estado de Santa Catarina. Revista de Educação PUC-Campinas, 21(2), 243-254.

Menegon, R. R., Canhoto, M. R. L., Lima, J. M., \& Romero, L. R. (2015). A importância dos projetos de extensão no processo de formação inicial de professores de Educação Física. Anais da Jornada do Núcleo de Ensino de Marília, Marília, 14. Marília: UNESP. Recuperado de https://www.marilia.unesp.br/Home/Eventos/2015/jornadadonucleo/aimportancia-dos-projetos-de-extensao.pdf

Nozaki. J. M., Ferreira, L. A., \& Hunger, D. A. C. (2015). Evidências formativas da extensão universitária na docência em Educação Física. Revista Eletrônica de Educação, 9(1), 228-241.

Paula, J. A. (2013). A extensão universitária: História, conceito e propostas. Interfaces - Revista de Extensão, 1(1), 5-23. Proença, I. C. L., Andrade, R. C., Tomazella, V. B., Palma, V. H., \& Souza, R. C. B. (2012). Diálogos da extensão universitária: Desafios e potencialidades nas práticas ambientais escolares do município de Lavras/MG. Revista Eletrônica do Mestrado em Educação Ambiental, 29, 1-18.

Santos, J. H. S., Rocha, B. F., \& Passaglio, K. T. (2016). Extensão Universitária e formação no Ensino Superior. Revista Brasileira de Extensão Universitária, 7(1), 23-28.

Souza, O. S. S. (2005). A extensão universitária e as universidades populares. Revista da FACED, 9, 253-264.

\footnotetext{
Como citar este artigo:
}

Peretiatko, J., Osternach, Y. M., Fernandes, R. M., Affonso, A. L. S., Rebeca, R., \& Kataoka, A. M. (2020). Contribuições da extensão universitária para a formação acadêmica a partir de um projeto de educação ambiental. Revista Brasileira de Extensão Universitária, 11(3), 417-427. https://periodicos.uffs.edu.br/index.php/RBEU/article/view/11457/pdf 